\title{
Online Learning on Quantitative Subjects during COVID-19: Identifying Factor Analysis for Teaching Effectiveness
}

Cheam Chai Li

To Link this Article: http://dx.doi.org/10.6007/IJARBSS/v11-i5/9865

DOI:10.6007/IJARBSS/v11-i5/9865

Received: 01 March 2021, Revised: 19 April 2021, Accepted: 05 May 2021

Published Online: 15 May 2021

In-Text Citation: (Li, 2021)

To Cite this Article: Li, C. C. (2021). Online Learning on Quantitative Subjects during COVID-19: Identifying Factor Analysis for Teaching Effectiveness. International Journal of Academic Research in Business and Social Sciences, 11(5), 127-138.

Copyright: (c) 2021 The Author(s)

Published by Human Resource Management Academic Research Society (www.hrmars.com)

This article is published under the Creative Commons Attribution (CC BY 4.0) license. Anyone may reproduce, distribute, translate and create derivative works of this article (for both commercial and non-commercial purposes), subject to full attribution to the original publication and authors. The full terms of this license may be seen at: http://creativecommons.org/licences/by/4.0/legalcode

Vol. 11, No. 5, 2021, Pg. 127 - 138

Full Terms \& Conditions of access and use can be found at http://hrmars.com/index.php/pages/detail/publication-ethics 


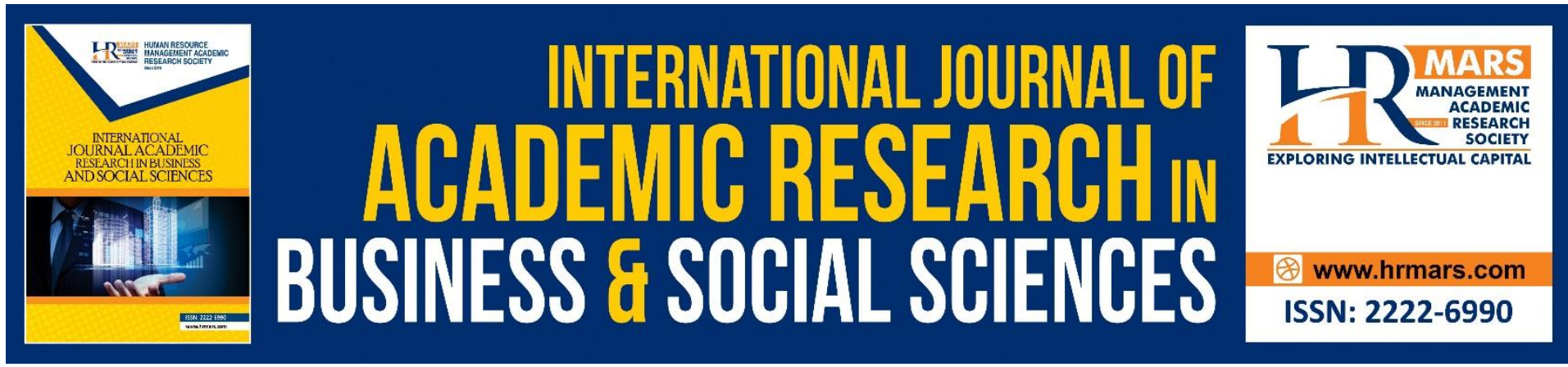

\title{
Online Learning on Quantitative Subjects during COVID-19: Identifying Factor Analysis for Teaching Effectiveness
}

\author{
Cheam Chai Li \\ Faculty of Business and Management, Universiti Teknologi MARA Kelantan, 18500 Machang, \\ Kelantan, Malaysia \\ Email: chailicheam@uitm.edu.my
}

\begin{abstract}
Online teaching and learning have witnessed tremendous growth in recent years. Thanks to progressive technological developments, researchers and educators are facilitated in conducting classes online to ensure teaching and learning processes remain on schedule. Such rapid growth in online learning renders it crucial for researchers to seek for understanding the manner in which an online classroom impacts learners. Previous studies have shown various e-learning and online learning tools that are effective for teaching and learning purposes in the health and dentistry professions. The current study was thus aimed at validating some effective online teaching and learning instruments for quantitative subjects, as well as organising and summarising the findings into a few core factors. Data were collected from undergraduates that had signed up for quantitative subjects using a Web-based instrument during the Coronavirus Disease 2019 COVID-19 pandemic, ranging from Monte Carlo and parallel analyses to principal components with varimax rotations. Subsequently, 20 items were reduced to three factors in which 16 of them were maintained, while the total variance explained was able to retain $75.382 \%$ of the original $100 \%$. Out of the 16 items, eight items were correlated with the attitude factor, while six and two items were correlated with educator and flexibility factors, respectively. It is hoped that these factors can be henceforth utilised as the basic approach for supporting online teaching and learning effectiveness in the education industry at present and for the future.
\end{abstract}

Keywords: Online Teaching, Teaching Effectiveness, Covid-19, Attitude, Educator, and Flexibility

\section{Introduction}

A recent discovery has been made pertaining a new novel coronavirus (2019-nCoV), which originated in Wuhan, the capital city of Hubei province in The People Republic of China. Following this, the coronavirus disease (COVID-19) pandemic has ravaged more than 200 countries globally and led to various adverse effects, forcing life, business, and tourism to a complete standstill (Jackson, Weiss, Schwarzenberg, and Nelson, 2020). To safeguard countries against further pandemic spread, many have opted for lockdown and the people's movement is limited. 
As a result of COVID-19, almost all of the industries worldwide are affected in which the education industry is not spared. However, distance education and learning are now possible thanks to the internet and recent technical advancements. According to United Nations Educational, Scientific and Cultural Organizatio UNESCO (2020), a majority of academic chiefs are now positioning online education as a solution to the pandemic, whereby the Malaysian public and private universities have followed suit accordingly. In fact, the e-learning industry has developed significantly in the last decade from an economic standpoint (Jesús ValverdeBerrocoso et al., 2020). Online learning denotes the fact that said activity can be done at any place and time, even when the students and instructors are not physically together (Parry et al., 2002; Miles and Leinster, 2007). Meanwhile, online teaching may differ from traditional courses across a number of ways, including instructor and learner roles, communication, interaction, and flexibility (Young, 2006). However, Bao (2020); Filius et al. (2019) have specified that transfer completely online requires significant planning and investments from all sectors. Besides, the significance of the educational environment for student learning has been increasingly acknowledged in recent years (Parry et al., 2002, Miles and Leinster, 2007). Regardlesss, some findings reveal that the distance in the online learning environment can also lead to isolation, frustration, boredom, overload, and low course completion rates (Berge 1999; Hara and Kling, 2000; Northrup, 2002).

In general, effective learning and education are characterised by rigorous coursework and effective pedagogical approaches aimed at enhancing the success level for all students (Rhodes, 2007). In sum, effective education is not just about teaching, but also learning. To enhance the learning element, students should be equipped with an optimal level of information and assignments (Preziosi and Alexakis, 2011), while they are also required to acquire a positive attitude (Selim, 2007). Contrarily, instructors will find it necessary to focus on enhanced learning, which is possible by being flexible and assimilating new subject content while concurrently adopting a variety of pedagogical methodologies (Douglas et al., 2008). Furthermore, it is vital that their teaching style is sufficiently effective to ensure that they are well-understood and their lessons can be applied by the learners (Gooden et al., 2009). In particular, Kim and Hannafin (2011) have posited that students that fail to develop an interest in their studies and the learning process are not able to progress well.

To break the chain of COVID-19 pandemic in Malaysia, no other substitutes are available pertaining to the feasible method of education other than online studies. In view of this, online teaching and learning were extensively conducted during the movement control order (MCO) period, ensuring the continuity of virtual classes without any obstructions for students to graduate-on-time (GOT). Previous studies have delineated various e-learning and online learning tools deemed effective for teaching and learning purposes in health-aligned professions, including dentistry (Moazami et al., 2014), Soltanimehr et al. (2019), and Varthis and Anderson (2016). However, courses involving an understanding of statistical concepts and calculation may render it a challenge for the teachers to achieve the student learning outcomes. In specific, the effectiveness of such method among these undergraduates is unknown while the findings may differ from case by case. In response to this, it is crucial for researchers and educators to consider this element of online education. Henceforth, the current study is aimed at validating some of the effective online teaching and learning instruments, as well as organising and summarising the findings into a few core factors. 


\section{Literature Review}

In general, many terms are synonymous with online learning, such as learning through the web, online learning, and instruction through computer assistance. According to Bertea (2009), some specialists are of the notion that it is a way of teaching in which multiple integrations of technology are sought. Meanwhile, others view the approach as a substitute for distance education, which is facilitated by the application of internet considered as an effective way of rapid communications.

Therefore, factors such as attitude, instructor, and flexibility may influence the online learning effectiveness experienced by students. In this context, attitude refers to the behaviour exhibited by students in online learning, whereby the negative learner attitudes in such environment include attributes like low level of computer skills, technological anxiety, computer hardware problems, poor study skills, low motivation, and inability to work independently (Smith et al. 2000, Govindasamy, 2001; Rosenberg, 2001). Sometimes, students may find online teaching to be boring and unlikable, whereas a prior work has revealed that this population could not sufficiently prepare for balancing their work, family, and social lives along with their study life in this environment. Thus, positive learner attitudes and behaviours towards online learning are important and imperative in attaining its acceptance and adoption (Selim, 2007; Lim et al, 2008).

Furthermore, the success of online learning depends on the role undertaken by instructors. The lack of option for normal face-to-face classroom education has rendered online teaching a necessity during the current era of COVID-19. The overnight shift into e-classrooms is understandably not easy for educators as they have to transform the entirety of their pedagogical approach for the purpose of meeting new conditions, while concurrently achieving the course learning objectives. This is consistent with Martin's (2019) opinion in which the emergence of online learning and lecture-based online classes along with the transformation of instructor roles both require a paradigm shift. Resistance to change will not aid any of them; contrarily, embracing and adapting to said changes are the key towards successful online education undertakings. Moreover, Bao's (2020) findings have specifically highlighted five high-impact principles for online education, one of which detailing the effective delivery of online instructional information. This aligns with Keeton's (2004) opinions that educators need to spend a lot of time to make effective strategies by giving online instructions. Educators should be able to use technological resources to achieve their teaching objectives. Methods of instruction and learning, curriculum preparation, and tests are all part of the teaching objectives (Elsie and Jane, 2018). These effective online instructions will then facilitate feedback from learners, spurring them to ask questions and broadening their horizon in line with the course content (Keeton, 2004).

A particular perk of online learning is the increased flexibility it offers, whereby this attribute is an interesting aspect embedded and allows students to plan their time for completion of courses available online. Here, Naidu (2017) has defined flexible learning as a state of being in which learning and teaching are increasingly freed from the limitations of time, place, and pace of study. Similarly, Saunders (2019) has stressed that e-learning must be flexible and accessible 24 hours a day. Alternatively, arguments by Soffer (2019) offer that student achievements are significantly related to the patterns of learning time and access they are afforded to the learning resources. In particular, the most common problem found in online 
classes is the fact that so much of time and flexibility allocated renders the students never finding the time to actually complete their tasks.

Corresponding to the discussion above, validation of effective online teaching and learning instruments is done to the three aforementioned factors, namely attitude, educator, and flexibility. This is rooted in their common prevalence in encounters with learners and educators alike.

\section{Methodology}

The sample consisted of the entire population of online undergraduate students in Universiti Teknologi Mara (UiTM) Kota Bharu that had signed up for two subjects, namely Business Analytics and Statistical Subjects, between March - July 2020. Accordingly, a total of 124 respondents were attained, following which only 113 usable responses were utilised after screening for blank and straight lining responses. The selected students were then contacted via WhatsApp group in which a link to the online survey was attached.

The questionnaire consisted of two sections, which were: 1) demographics, and 2) online teaching effectiveness. The latter section encompasses 16 items (i.e. out of the original 20 questions) and employs 7-point Likert scale ranging from 1 (strongly disagree) to 7 (strongly agree) as shown in Table 1. The questionnaire were adapted and adopted from the works of Bolliger and Wasilik (2009); Shea, Chun, and Pickett (2006); and Kelly, Lyng, McGrath, and Cannon (2008). Meanwhile, the remaining questions elicited reponses on respondent demography.

This study first applied the statistical method of parallel analysis by using the Statistical Package for the Social Sciences (SPSS) scree plot and Monte Carlo simulation to determine the number of components that were to be retained as the factors for analysis purposes. Then, the Kaiser-Meyer-Olkin Measure (KMO) test was conducted to check for data suitability preceding the factor analysis, following which the outcome was found to be significant. Accordingly, factor analysis was undertaken; it is one of the most useful methods for studying and validating the internal structure of instruments (Nunnally 1978; Pedhazur \& Schmelkin 1991; Kieffer 1999; Henson \& Roberts 2006). Next, the principal component analysis (PCA) with varimax rotation was applied to investigate the instruments in detail. Finally, the data were checked for reliability and normality using relevant tests in view of their kurtosis and skewness outcomes. 
Table 1. Survey instrument

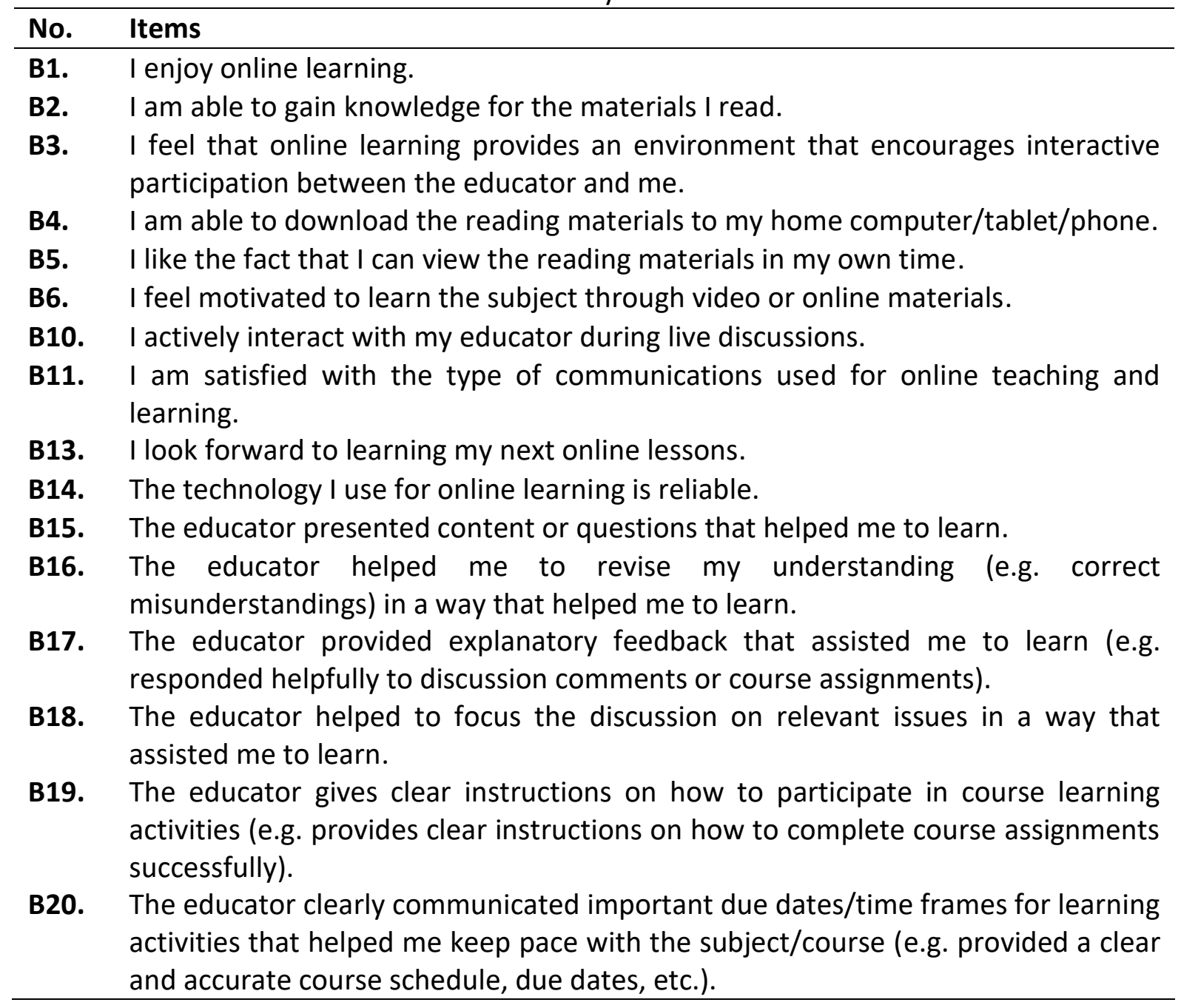

\section{Findings and Discussion}

Table 2 shows the basic demography profile of all 113 participants for the study in which the female gender dominates at $75.2 \%$ (85), while the male participants amount to $24.8 \%(28)$. A majority of the sample $(97.3 \%, 100)$ were of the age range between $20-23$ years. Meanwhile, more than half $(59.3 \%, 67)$ of the participants were in Semester 4 , whereas the remaining $37.2 \%(42)$ and $3.5 \%(4)$ were in Semesters 3 and 5, respectively. 
Table 2: Basic Demographic Profile

\begin{tabular}{lll}
\hline & $\mathbf{N}$ & $\%$ \\
\hline $\begin{array}{lll}\text { Gender } \\
\text { Female }\end{array}$ & 85 & 75.2 \\
Male & 28 & 24.8 \\
Age & & \\
\hline $20-21$ & & \\
$22-23$ & 53 & 46.9 \\
$>24$ & 57 & 50.4 \\
Semester & 3 & 2.7 \\
3 & & \\
4 & & \\
5 & 42 & 37.2 \\
\hline
\end{tabular}

Corresponding to the aforementioned methodology, the findings obtained are presented below. Figure 1 shows a visualisation of parallel analysis results, whereby the eigenvalues obtained from the scree plot (refer 'analysis' line) is compared with the Monte Carlo simulation (refer 'random' line). Accordingly, the Monte Carlo and parallel analyses outcomes indicated that the dataset underlined three specific factors as the most suitable attributes. In other words, the number of factors extracted by using said scientific tools suggested these three factors.

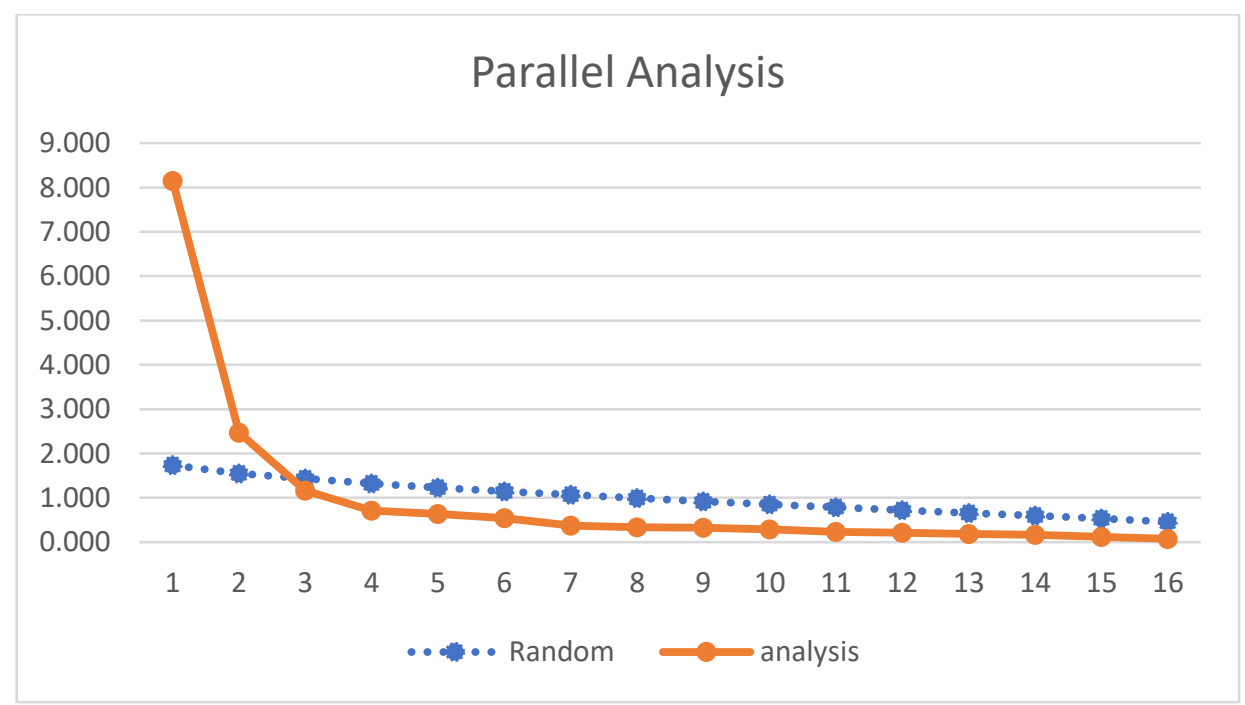

Figure 1: Parallel Analysis

Table 3: Kaiser-Meyer-Olkin Measure of Sampling Adequacy

\begin{tabular}{lll}
\hline Kaiser-Meyer-Olkin Measure of Sampling Adequacy. & $\mathbf{0 . 9 1 3}$ \\
\hline Bartlett's Test of Sphericity & Approx. Chi-Square & 1531.559 \\
& df & 120 \\
& Sig. & 0 \\
\hline
\end{tabular}


Next, determining whether the data was suitable for factor analysis was undertaken by implementing the KMO Measure of Sampling Adequacy. The value generated denoted 0.913, which indicated a meritorious index due to the value exceeding 0.50 and that the KMO outcome met the requirement. Besides, this justified the necessity for performing factor analysis. Concurrently, the Barlett's test yielded a value of 1531.56 with a significance of 0.00 , thereby suggesting the lack of correlation between variables tested. Thus, factor analysis could be conducted, as per the findings of these two tests. All results are as exhibited in Table 3.

In the process, some of the problematic items were eliminated from the item list, whereby the updated list included 16 items out of the original 20 items. Accordingly, anti-image correlation is calculated by the Measures of Sampling Adequacy (MSA), where the value is obtained by looking at the diagonal value with ' $a$ ' alphabet next to each value in the SPSS (refer Table 4). Here, 16 variables were thus found to meet MSA requirements out of all tested ones in which they generated values greater than 0.5 . Thus, all variables incorporated in the study were deemed feasible for further factor analysis. From the results of three-factor validity tests, it could be concluded that the empirical indicators successfully fulfilled the denoted requirements as the variable shaper.

Table 4: Results of Factor Analysis

\begin{tabular}{lccccc}
\hline Items & $\mathbf{1}$ & $\mathbf{2}$ & $\mathbf{3}$ & Communalities & $\begin{array}{c}\text { Anti-image } \\
\text { correlation }\end{array}$ \\
\hline B1 & $\mathbf{0 . 7 5 6}$ & 0.122 & 0.330 & 0.696 & $0.919^{\mathrm{a}}$ \\
B2 & $\mathbf{0 . 6 8 0}$ & 0.274 & 0.302 & 0.629 & $0.944^{\mathrm{a}}$ \\
B3 & $\mathbf{0 . 7 9 5}$ & 0.172 & 0.241 & 0.720 & $0.922^{\mathrm{a}}$ \\
B4 & 0.276 & 0.337 & $\mathbf{0 . 7 8 0}$ & 0.798 & $0.883^{\mathrm{a}}$ \\
B5 & 0.443 & 0.153 & $\mathbf{0 . 7 3 8}$ & 0.764 & $0.881^{\mathrm{a}}$ \\
B6 & $\mathbf{0 . 7 9 6}$ & 0.121 & 0.362 & 0.779 & $0.907^{\mathrm{a}}$ \\
B10 & $\mathbf{0 . 6 4 1}$ & 0.387 & -0.331 & 0.670 & $0.930^{\mathrm{a}}$ \\
B11 & $\mathbf{0 . 7 9 7}$ & 0.307 & 0.100 & 0.739 & $0.925^{\mathrm{a}}$ \\
B13 & $\mathbf{0 . 8 3 8}$ & 0.183 & 0.072 & 0.741 & $0.886^{\mathrm{a}}$ \\
B14 & $\mathbf{0 . 6 2 4}$ & 0.355 & 0.336 & 0.628 & $0.922^{\mathrm{a}}$ \\
B15 & 0.330 & $\mathbf{0 . 7 9 5}$ & 0.188 & 0.775 & $0.939^{\mathrm{a}}$ \\
B16 & 0.240 & $\mathbf{0 . 9 0 9}$ & 0.120 & 0.898 & $0.873^{\mathrm{a}}$ \\
B17 & 0.096 & $\mathbf{0 . 8 5 3}$ & 0.297 & 0.825 & $0.895^{\mathrm{a}}$ \\
B18 & 0.167 & $\mathbf{0 . 9 0 4}$ & 0.163 & 0.872 & $0.934^{\mathrm{a}}$ \\
B19 & 0.391 & $\mathbf{0 . 7 5 9}$ & 0.046 & 0.731 & $0.926^{\mathrm{a}}$ \\
B20 & 0.169 & $\mathbf{0 . 8 7 5}$ & 0.035 & 0.795 & $0.915^{\mathrm{a}}$ \\
\hline Cronbach & 0.920 & 0.940 & 0.812 & & \\
Eigenvalue & 8.504 & 2.422 & 1.135 & & \\
\% of Variance & 53.15 & 15.136 & 7.096 & & \\
\hline
\end{tabular}

Communality can be described as the variance in observed variables that are accounted for by a common factor, which is more relevant to Exploratory Factor Analysis (EFA). Based on Table 4, all 16 items tested in this study meet the communality requirement for an extraction value higher than 0.5: the higher the communality value, the tighter the relationship perceived between the variable and the established factors. For instance, the 
value of B1 at 0.696 indicated that it could explain the factor equivalent to $69.6 \%$. Likewise, the values for all of the other items were above 0.5 , revealing their capability for explaining the factor well.

Furthermore, the total variance explained revealed the formation of three factors in the study based on the eigenvalue (>1). Consistent with the outcomes of parallel analysis in Figure 1, 16 items are then grouped into these three factors. The percentage of variance explained by reducing from 16 items to three factors led to the finding that the study was able to retain $75.382 \%$ of original $100 \%$, whereas the loss was around $24.618 \%$.

The final step in this study was factor determination in which rotated component matrix was implemented to check the loadings and determine what item would go to which factor, thus showing the correlation between the items and the construct. With no independent and dependent variables in the dataset, PCA and varimax rotation were applied and revealed the loading and cross loading outcomes greater than 0.5 (Table 4).

Here, rotated component matrix shows the loading factor coefficients for all 16 items tested in Factors 1, 2, and 3 factors as seen in Table 4. As mentioned earlier, 20 items were reduced to three factors with 16 of them maintained. The table displays items B1, B2, B3, B6, $\mathrm{B} 10, \mathrm{~B} 11, \mathrm{~B} 13$, and B14 that correlate with Factor 1, yielding the values of $0.756,0.680,0.795$, $0.796,0.641,0.797,0.838$, and 0.641 , respectively. Meanwhile, values that correlated with Factor 2 were seen for items B15, B16, B17, B18, B19 and B20 at 0.795, 0.909, 0.853, 0.904, 0.759 , and 0.875 respectively. Alternatively, Factor 3 correlated with items B4 and B5 with values of 0.780 and 0738 , respectively. Following this, observing the item loadings on each factor allowed Factors 1, 2, and 3 to be identified accordingly, which awere then labelled as attitude (Selim, 2007, Lim et al., 2008); educator (Gooden et al., 2009; Martin, 2019; Bao, 2020); and flexibility (Soffer, 2019; Saunders, 2019; Naidu, 2017), respectively.

Next, the reliability tests for the attitude, educator and flexibility factors were run accordingly. Nunnally (1978) has specified the reliability for established scales ranging from 0.8-0.9. Subsequently, this study yielded Cronbach's alpha values greater than 0.80 for all three factors, generating $0.92,0.94$, and 0.812 for attitude, educator, and flexibility factors, respectively (Table 4).

Lastly, a normality test is conducted for the factors, whereby Table 5 displays the univariate skewness and kurtosis outcomes for attitude, educator, and flexibility. The rule of thumb is values of \pm 1 and \pm 7 for skewness and kurtosis, respectively. Here, attitude, educator, and flexibility revealed skewness and kurtosis outcomes within the specified ranges, thus assuring that the three factors were normally distributed.

Table 5: Normality Test

\begin{tabular}{lll}
\hline & Skewness & Kurtosis \\
\hline Attitude & -0.284 & 0.096 \\
Educator & -0.666 & 0.040 \\
Flexibility & -1.048 & 0.671 \\
\hline
\end{tabular}

\section{Conclusion}

The aim of the current study was to validate some of the effective online teaching and learning instruments for quantitative subjects. As such, Monte Carlo and scree plot parallel analyses carried out along with PCA with varimax rotations revealed mathematical and scientific justifications alike, allowing researchers to make critical decisions and produce 
meaningful factor structures. Here, the three factors were identified as attitude, educator, and flexibility.

From the findings, the performance exhibited by students and instructors is found to be equally important in making online education effective. On one hand, positive student attitudes towards online learning are critical to their readiness and inclusion in the process and the population must develop a self-efficacy attitude in the first place to attain effective learning. In contrast, instructors must wield their interactive pedagogy ability and motivation skills to make teaching effective. One must note that the new educational norm renders flexible teaching and learning processes highly necessary to ensure meaningful learning is achieved in the best possible way.

The present study successfully delineates several key insights essential for future online education improvement and development. It is hoped that the factors identified can be henceforth utilised as a basic approach to support online teaching and learning effectiveness in the education industry whether at present and for the future. Apart from the three factors mentioned, the pandemic has also taught us that adaptability is necessary to survive the crisis. It is the effective communication that is compulsory in stimulating learning and achieving satisfaction, confidence, and trust between educators and learners. Hence, it is suggested that future research efforts focus on communication and adaptability to evaluate online education effectiveness. Additionally, other pertinent factors such as technology and anxiety are worth considering too.

\section{Acknowledgements}

I would like to take the opportunity to thank the reviewers for giving me such a great and priceless feedbacks on this paper.

\section{References}

Bao, W. (2020). COVID-19 and online teaching in higher education: A case study of Peking University. Hum Behav \& Emerg Tech. 2, 113-115. https://doi.org/10.1002/hbe2.191

Berge, Z. L. (1999). Interaction in post-secondary, Web-based learning and teaching. Educational Technology 39 (1), 5-11.

Bertea, P. (2009). Measuring Students' Attitude towards Online learning. A Case Study. A paper presented in the 5th International Scientific conference on online learning and software of Education, Bucharist.

Bolliger D. U., and Wasilik, O. (2009). Factors Influencing Faculty Satisfaction with Online Teaching and Learning in Higher Education, Distance Education, 30(1), 103-116.

Douglas, A., Miller, B., Kwansa, F., and Cummings, P. (2008). Students' perceptions of the usefulness of a virtual simulation in post- secondary hospitality education. Journal of Teaching in Travel and Tourism. 7(3), 1-19.

Filius, R. M., Kleijn, R. A. M., Uijl, S. G., Prins, F. J., Rijen, H. V. M., \& Grobbee, D. E. (2019). Audio peer feedback to promote deep learning in online education. Journal of Computer Assisted Learning, 35(5), 607-619. https://doi.org/10.1111/jcal.12363

Gooden, D., Preziosi, R., and Barnes, F. (2009). An examination of Kolb's learning style inventory. American Journal of Business Education. 2(3), 57-62.

Govindasamy, T. (2001). Successful Implementation of e-learning: Pedagogical Considerations. The Internet and Higher Education. 4(3-4), 287-299. 
Hara, N., and Kling, R. (2000). Students' distress with a Web-based distance education course. Information, Communication and Society. 3(4), 557-579.

Henson, R. K., and Roberts, J. K. (2006). Use of Exploratory Factor Analysis in Published Research: Common Errors and Some Comment on Improved Practice. Educational and Psychological Measurement. 66(3), 393-416.

Jackson, J., Weiss, M. A., Andres, B. S., Rebecca, M. N. (2020) Global Economics Effects of Covid19. Congressional Research Service. https://fas.org/sgp/crs/row/R46270.pdf

Keeton, M. T. (2004). Best online instructional practices: Report of phase I of an ongoing study. Journal of Asynchronous Learning Networks. 8(2), 75-100.

Kieffer, K. M. (1999). An introductory primer on the appropriate use of exploratory and confirmatory factor analysis. Research in the Schools. 6, 75-92.

Kim, M., and Hannafin, M. (2011). Scaffolding 6th graders' problem-solving in technologyenhanced science classrooms: a qualitative case study. Instructional Science: An International Journal of the Learning Sciences. 39(3), 255-282.

Martin, F., Budhrani, K., Kumar, S., \& Ritzhaupt, A. (2019). Award-winning faculty online teaching practices: Roles and competencies. Online Learning, 23(1), 184-205. doi:10.24059/olj.v23i1.1329

Miles, S., Leinster, S. J. (2007). Medical students' perceptions of their educational environment: Expected versus actual perceptions. Med Educ. 41, 265-272.

Moazami, F., Bahrampour, E., Azar, M. R., Jahedi, F., Moattari, M. (2014) Comparing two methods of education (virtual versus traditional) on learning of Iranian dental students: a post-test only design study. BMC Med Educ. 14(45).https://doi.org/10.1186/14726920-14-45.

Naidu, S. (2017) How flexible is flexible learning, who is to decide and what are its implications? Distance Education. 38(3), 269-272.

Northrup, P. T. (2002). Online learners' preferences for interaction. The Quarterly Review of Distance Education. 3(2), 219-226.

Nunnally, J. C. (1978). Psychometric theory (2nd ed.). New York: McGraw-Hill.

Parry, J., Mathers, J., Al-Fares, A., Mohammad, M., Nandakumar, M., Tsivos, D. (2002). Hostile teaching hospitals and friendly district general hospitals: Final year students' views on clinical attachment locations. Med Edu. 36, 1131-1141.

Pedhazur, E. J., \& Schmelkin, L. P. (1991). Measurement, design, and analysis: An integrated approach. Hillsdale, NJ: Lawrence Erlbaum.

Preziosi, R., and Alexakis, G. (2011). A comparison of traditional instructional methods and accelerated learning methods in leadership education. International Leadership Journal. 3(1), 79-89.

Robinson, C., and Taylor, C. (2007). Theorizing student voice: values and perspectives. Improving Schools. 10(5), 5-17.

Rosenberg, M. J. (2001). Online learning, strategies for delivering knowledge in the digital age. New York: McGraw-Hill.

Saunders, S. (2019). Flexible and accessible: How to make online learning effective, Studiosity. https://www.studiosity.com/blog/flexible-and-accessible-how-to-make-onlinelearning-effective

Selim, H. M. (2007). Critical success factors for online learning acceptance: Confirmatory factor models. Computers and Education. 49, 396-413.

Shivangi Dhawan (2020). Online Learning: A Panacea in the Time of COVID-19 Crisis. Journal of Educational Technology Systems. 49(1), 5-22. 
Smith, B., Caputi, P., \& Rawstorne, P. (2000). Differentiating computer experience and attitudes toward computers: an empirical investigation. Computer in Human Behavior. $16,59-81$.

Young, S. (2006). Student Views of Effective Online Teaching in Higher Education. The American Journal of Distances education. 20(2), 65-77.

UNESCO. (2020). Global Education Coalition-290-million students out school due-COVID-19. In Unesco. https://en.unesco.org/news/290-million-students-out-school-due-covid-19unesco-releases-first-globalnumbers-and-mobilizes.

Varthis, S., Anderson, O. R. (2016) Students' perceptions of a blended learning experience in dental education. Eur J Dent Educ. 1-7. https://doi.org/10.1111/eje.12253 